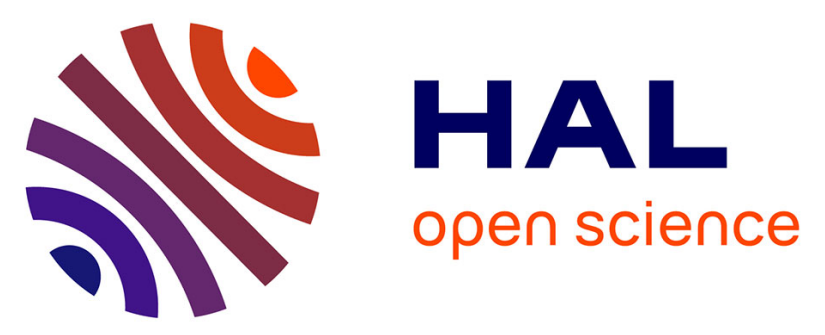

\title{
Absence of carrier recombination associated with the defect pool model in intrinsic amorphous silicon layers: Evidence from current-voltage characteristics on p-i-n and n-i-p solar cells
}

J. Deng, J. M Pearce, R J Koval, V. Vlahos, R. Collins, C R Wronski, R. Wronski

\section{To cite this version:}

J. Deng, J. M Pearce, R J Koval, V. Vlahos, R. Collins, et al.. Absence of carrier recombination associated with the defect pool model in intrinsic amorphous silicon layers: Evidence from currentvoltage characteristics on p-i-n and n-i-p solar cells. Applied Physics Letters, 2003, 82 (18), pp.30233025. 10.1063/1.1571985 . hal-02120546

\section{HAL Id: hal-02120546 \\ https://hal.science/hal-02120546}

Submitted on 6 May 2019

HAL is a multi-disciplinary open access archive for the deposit and dissemination of scientific research documents, whether they are published or not. The documents may come from teaching and research institutions in France or abroad, or from public or private research centers.
L'archive ouverte pluridisciplinaire HAL, est destinée au dépôt et à la diffusion de documents scientifiques de niveau recherche, publiés ou non, émanant des établissements d'enseignement et de recherche français ou étrangers, des laboratoires publics ou privés. 


\title{
Absence of carrier recombination associated with the defect pool model in intrinsic amorphous silicon layers: Evidence from current-voltage characteristics on $\boldsymbol{p}-\boldsymbol{i}-\boldsymbol{n}$ and $\boldsymbol{n}-\boldsymbol{i}-\boldsymbol{p}$ solar cells
}

\author{
J. Deng, J. M. Pearce, R. J. Koval, V. Vlahos, R. W. Collins, and C. R. Wronski ${ }^{\text {a) }}$ \\ Center for Thin Film Devices, the Pennsylvania State University, University Park, Pennsylvania 16802
}

(Received 20 December 2002; accepted 7 March 2003)

\begin{abstract}
Forward bias current-voltage characteristics $\left(J_{D}-V\right)$ were studied for both $p-i-n$ (superstrate) and $n-i-p$ (substrate) $(a-\mathrm{SiC}: \mathrm{H} p) /(a-\mathrm{Si}: \mathrm{H} i)$ solar-cell structures having different $p / i$ interface layers and different thickness $i$-layers. Contributions of the $p / i$ interfaces to the $J_{D^{-}} V$ characteristics were separated, and the dependence on the thickness of the $i$-layers was established. Equivalence was observed in a comparison of the characteristics of $p-i-n$ and $n-i-p$ cells. The various $J_{D}-V$ characteristics are found to be consistent with uniform densities of defects in the $i$-layers, and thus inconsistent with the spatially varying large densities of defects predicted for solar-cell structures by the defect pool model. (C) 2003 American Institute of Physics.
\end{abstract}

[DOI: $10.1063 / 1.1571985]$

The performance and stability of hydrogenated amorphous silicon $(a-\mathrm{Si}: \mathrm{H})$ solar cells are expected to depend on the intrinsic ( $i$ )-layer densities of states in the band gap; the $i$-layer recombination kinetics and mobility gaps; the properties of doped layer, including their DOS, recombination, and mobility gaps; the properties of the interfaces between the doped and $i$-layers; and the front and back contacts. There have been numerous studies addressing these dependences, in particular, the effects of the recombination kinetics and the nature of the defects in the $i$-layers for both $p-i-n$ (superstrate) and $n-i-p$ (substrate) cells. The inherent complexity of $a-\mathrm{Si}: \mathrm{H}$ and its solar-cell structures has made it difficult to interpret measured device characteristics in a straightforward manner. In fact, the analysis is generally carried out by computer modeling, which involves large numbers of parameters, many of which have yet to be established reliably from experiments. As a consequence, various models have been suggested to describe the carrier recombination in the $i$-layers of $p-i-n$ and $n-i-p$ cell structures based on proposed differences in the nature and densities of defects (DODs), not only in the bulk, but also at both $p / i$ and $n / i$ interfaces. ${ }^{1,2}$ Conflicting proposals have been made, whereby in one model, the $i$-layer is considered in terms of a homogeneous distribution of defects, whereas in the other, a spatially nonuniform DOD is invoked as a consequence of the defect pool model. ${ }^{3,4}$ According to the defect pool model, the thermodynamic equilibration in the density of dangling bond defects in the $i$-layer depends on the position of the Fermi level, $E_{\mathrm{F}}$. The proximity of $E_{\mathrm{F}}$ to the conduction and valence bands near the $n$ and $p$ contacts, respectively, results in spatially varying higher densities of charged defects, relative to those of the bulk $i$-layer, where $E_{\mathrm{F}}$ is near midgap. This results in an asymmetry in defect distribution between $p-i-n$ and $n-i-p$ cell structures. Evidence for such nonuniform defect distributions has been recently presented by Kroon and Van Swaaij ${ }^{5}$ based on their results for the forward

${ }^{a)}$ Electronic mail: crwece@engr.psu.edu bias, dark-current-voltage $\left(J_{D}-V\right)$ characteristics of $p-i-n$ and $n-i-p a-\mathrm{Si}: \mathrm{H}$ cells. In Ref. 5, it is claimed that three observations, the constant diode quality factors between 1 and 2 over extended regions of voltage, the absence of a thickness dependence, and the nonequivalence of the characteristics in a comparison of $p-i-n$ and $n-i-p$ cell structures can be attributed solely to spatially inhomogeneous densities of defects associated with the defect pool model.

In this letter, we report a study of $J_{D^{-}} V$ characteristics for $p-i-n$ and $n-i-p$ cell structures having different $i$-layer thicknesses, in which the contributions of the recombination in the $i$-layers and at the $p / i$ interfaces have been identified and separated. No evidence is found for inhomogeneous densities of defects in the intrinsic layers as reported earlier. ${ }^{5}$ The contributions of recombination at the $p / i$ interfaces to the $J_{D}-V$ characteristics were identified by controlling such recombination with intrinsic $a-\mathrm{Si}: \mathrm{H}$ having different band gaps in a $200-\AA$ region adjacent to the $p$-layers. Such an approach has been utilized in the systematic improvement of the 1-sun $V_{\mathrm{OC}}$ in $p-i-n$ cells. ${ }^{6}$

The $a-\mathrm{Si}: \mathrm{H}$ solar cells were fabricated by rf plasmaenhanced chemical vapor deposition at a substrate temperature of $200{ }^{\circ} \mathrm{C}$ under conditions described previously, ${ }^{7}$ using $\mathrm{SiH}_{4}$ diluted with $\mathrm{H}_{2}$ such that the dilution ratio $R$ $=\left[\mathrm{H}_{2}\right] /\left[\mathrm{SiH}_{4}\right]$ is set at values from 0 to 40 for the interfaces and bulk $i$-layers. The $p-i-n$ cell structures consisted of specular $\quad \mathrm{SnO}_{2} / p a-\mathrm{SiC}: \mathrm{H}(250 \AA) / i \quad a-\mathrm{Si}: \mathrm{H} / n \mu c-\mathrm{Si}: \mathrm{H}$ $(350 \AA) / \mathrm{Cr}$, and the $n-i-p$ structures consisted of glass $/ \mathrm{Cr} / n \quad a-\mathrm{Si}: \mathrm{H}(350 \AA) / i \quad a-\mathrm{Si}: \mathrm{H} / p a-\mathrm{SiC}: \mathrm{H}(250 \AA) /$ ITO. $R=0$ and $R=10 i$-layers were incorporated with thicknesses ranging from 0.2 to $1.5 \mu \mathrm{m}$. The $200-\AA a-\mathrm{Si}: \mathrm{H}$ interface layers consisted of $R=0,10$, and 40 films whose band gaps $\left(\alpha_{2000}\right)$ were $1.80,1.86, \sim 1.95 \mathrm{eV}$ respectively. To minimize the contributions of shunts, cell structure areas of 0.02 and $0.05 \mathrm{~cm}^{2}$ were used. For $p-i-n$ cells these areas were defined by reactive ion etching of the $n \mu c-\mathrm{Si}$ :H layers. Due to the low conductivity of the $\mathrm{SiC} p$-layers, however, it was possible to obtain leakage currents 


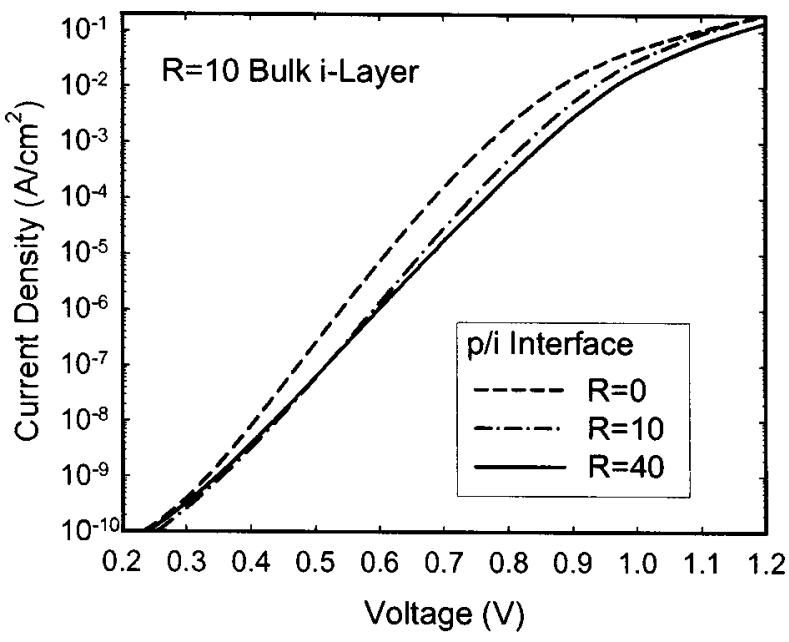

FIG. 1. Evolution of $J_{D}-V$ characteristics for $p-i-n$ cell structures with $0.4 \mu \mathrm{m}, R=10 a$-Si:H $i$-layers when the $p / i$ interface $R$ value is increased from $R=0$ to 40 .

$<10^{-10} \mathrm{~A} / \mathrm{cm}^{2}$ in the $n-i-p$ cells even without etching. A four-probe technique was used to eliminate any extraneous series resistance effects. Care was taken to ensure that the equilibrium currents were measured at low biases and that no defects were introduced by double injection in the high forward bias regions. The measurements were carried out in 50 $\mathrm{mV}$ increments at $25^{\circ} \mathrm{C}$ on cells in their annealed states after heating for $4 \mathrm{~h}$ at $170^{\circ} \mathrm{C}$. They were highly reproducible over the entire voltage range, apart from occasional shunting contributions at the very low biases.

The contributions of the $i$-layers to $J_{D^{-}} V$ could be established clearly from the results obtained on structures designed to reduce recombination at the $p / i$ interface by widening the band gap of the $a$-Si:H there. This is illustrated by Fig. 1 wherein the $J_{D}-V$ characteristics are shown for $p-i-n$ cell structures with $0.4-\mu$ m-thick $R=10 \quad i$-layers. The $J_{D}-V$ characteristics up to $\sim 0.8 \mathrm{~V}$ in Fig. 1 are consistent with carrier transport attributed to the injection of electrons and holes from the $n$ and $p$ contacts, respectively, followed by their diffusion and ultimate recombination. In this voltage regime, the recombination currents exhibit an exponential dependence on bias before becoming limited by the injection of carriers from the contacts as well as by a transition from diffusive to drift transport. ${ }^{8}$ Several features of the $J_{D^{-}}-V$ characteristics in Fig. 1 can be identified, as the recombination at the $p / i$ interface is reduced and the contribution from the $i$-layer becomes prominent. In the case of the cell with $R=0 \mathrm{p} / \mathrm{i}$ interface, the large interface recombination results in the high currents that exhibit an effective diode quality factor $m^{*}=1.2$. Reducing this recombination results in strikingly different $J_{D}-V$ characteristics with lower currents over extended voltage regions, and a higher $m$ value of 1.4. In the case of the $R=10 \mathrm{p} / \mathrm{i}$ interface, $m=1.4$ in the region up to $\sim 0.5 \mathrm{~V}$. For $V>0.5 \mathrm{~V}, m$ decreases to a value closer to $m^{*}$ before being limited by carrier injection from the contacts. Further reduction of the recombination at the $p / i$ interface with the $R=40$ layer extends the region with $m=1.4$ to higher voltages. Evidently, the extension of the region dominated by recombination in the bulk is due to the reduction of recombination at the $p / i$ interface, as previously observed by Pearce et al. ${ }^{9}$ similar effect and lead to $m<2$ over an extended voltage
observed by Pearce et al. ${ }^{9}$
Downloaded 18 May 2003 to 130.203 .197 .229 . Redistribution subject to AlP license or copyright, see http://ojps.aip.org/aplo/aplcr.jsp

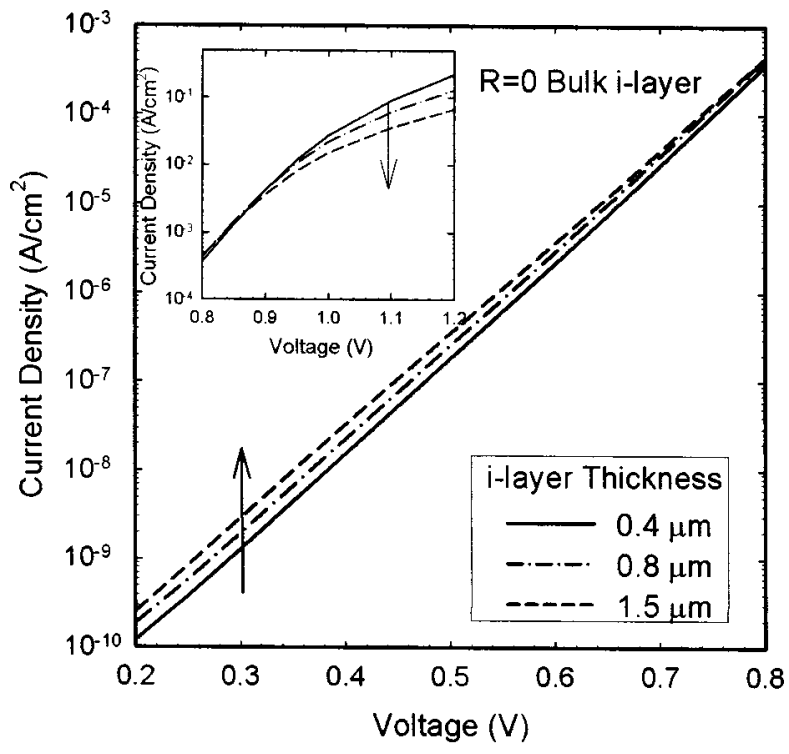

FIG. 2. The $J_{D^{-}}-V$ characteristics of $p-i-n$ cell structures with $0.4-, 0.8-$,

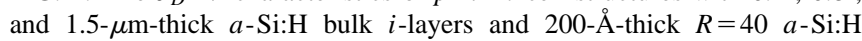
$i$-layers incorporated at the $p / i$ interface. Shown in the inset is the opposite trend in the currents with thickness, when carrier transport is determined by

The $J_{D}-V$ characteristics just discussed can be explained by diffusion/recombination transport in accordance with the work of Lips ${ }^{8}$ and by the Shockley-Reed-Hall $(\mathrm{SRH})$ recombination mechanism ${ }^{10}$ without invoking the presence of large DODs in the $i$-layer close to the $p / i$ interface. In the SRH mechanism, whereby the electrons $(n)$ and holes $(p)$ recombine through states in the gap, the recombination rate $r$ depends on the concentrations $n$ and $p$, the nature of the gap states, and their densities. Both $n$ and $p$ in the $i$-layer, as well as $r$, increase exponentially with applied forward bias $V_{A}$. For the case of the $p / i$ interface, the recombination is determined by defect states at the interface rather than in the bulk and $p \gg n$. Consequently, the recombination current depends solely on the value of $n$, and its exponential increase is determined by the entire voltage applied across the $i$-layer. Thus, the effective diode quality factors are close to one as in the case of $m^{*}=1.2$ in Fig. 1. In fact, the precise value can be attributed to a variety of factors related to the $p / i$ interface recombination. ${ }^{11}$ Because both $n$ and $p$ vary exponentially across the $i$-layer, the dependence of the recombination currents in the bulk on $V_{A}$ is more complex, particularly in the presence of a continuous distribution of states that act as recombination centers. It is well established that the diode quality factor is 2 in the case of recombination through a single defect level.

The recombination currents in the bulk $i$-layer are dominated by the region where the highest recombination rate $r_{\max }$ is located. The width of such a region is inversely proportional to the electric field. It has been shown analytically tion of defect states versus energy away from midgap results in a constant diode quality factor that is reduced from the value of 2 . The extent to which this decrease occurs depends on how rapidly the densities of gap states increase versus energy above and below midgap. Defect distributions that also increase rapidly, but of nonexponential form, have a drift rather than diffusion. by Berkel et al. ${ }^{12}$ that an exponentially increasing distribu- 


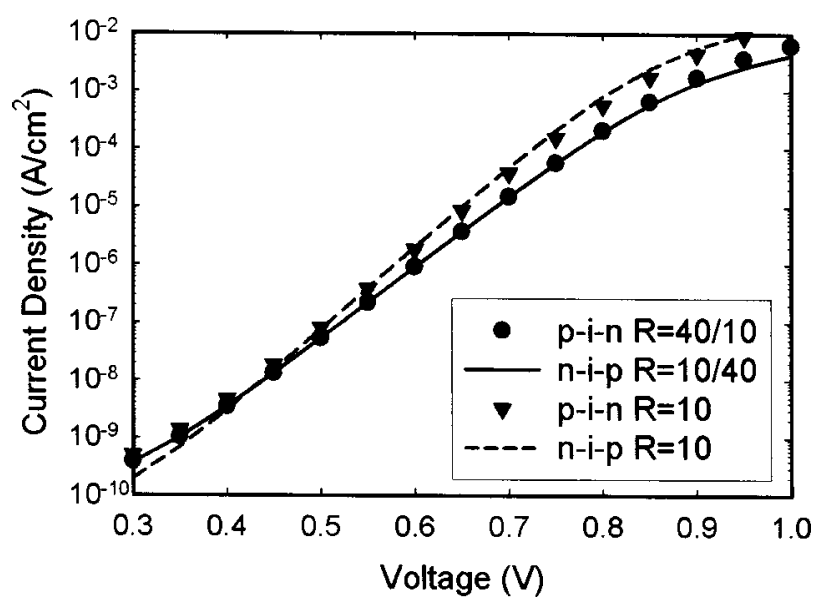

FIG. 3. The $J_{D}-V$ characteristics of $p-i-n$ and $n-i-p$ cell structures with $0.4-\mu \mathrm{m}, R=10 i$-layers, and with $R=10$ or $R=40 a$-Si:H at the $p / i$ interfaces.

region. The value of $m=1.4$ observed in Fig. 1 between $\sim 0.2$ and $0.7 \mathrm{~V}$ can be explained by the increase in $r_{\max }$ due to a sharp increase in the density of gap states as, for example, with Gaussian distributions that occur over regions of $\sim 0.3 \mathrm{eV}$ above and below midgap.

The absence of very large DODs in the region of the $i$-layer near the $p / i$ interface, the region that dominates $r_{\max }$, is clearly established from the "elusive" 5,13,14 $i$-layer thickness dependence of the $J_{D}-V$ characteristics. This is illustrated in Fig. 2, where the results are shown for $p-i-n$ cell structures with $R=0 \quad i$-layers $0.4-, 0.8-, 1.5-\mu$ m-thick, in which the $p / i$ interface recombination has been minimized by incorporating a $200-\AA R=40 a$-Si:H layer there. A systematic increase with thickness can be seen in the bulk recombination dominated currents due to the decrease in electric field with thickness that widens the region where $r_{\max }$ occurs. There is a nonlinear dependence of the bulk recombination currents on thickness that is attributed to the effects of space charge in the $i$-layer on the electric field, which then does not scale precisely with thickness. In the inset of Fig. 2, the corresponding $J_{D}-V$ characteristics at higher forward biases are shown. The expected decrease in the current with thickness is observed when the carrier transport becomes drift dominated.

These results are in conflict with the predictions of the defect pool model. This model also predicts that the sequence in which the $p$ and $n$ layers are deposited should lead to a significant difference between the $J_{D}-V$ characteristics of $p-i-n$ and $n-i-p$ solar cell structures. No such effect is found, however, in the cells deposited in this study. These include cells having $R=0$ and $R=10 i$-layers and in addition cells having different $p / i$ interface layers. This is illustrated in Fig. 3, where the results are shown for cells with $0.4-\mu \mathrm{m}-$ thick $R=10 i$-layers and $R=10,40 p / i$ interface layers.

By clearly separating the $p / i$ interface and bulk contributions to the $J_{D}-V$ characteristics of $a-\mathrm{Si}: \mathrm{H}$ cell structures, it has been possible to characterize the recombination in the $i$-layers. An increase in recombination currents is found by increasing both the thickness as well as the densities of gap states in the $i$-layers. The various $J_{D^{-}} V$ characteristics are consistent with $i$-layers having continuous distributions of states versus energy across the gap as well as homogeneous densities of defects versus position across the device structure. This finding, along with the observed equivalence between the characteristics of $p-i-n$ and $n-i-p$ cells, points to the absence of any large and spatially varying distributions of defects, as predicted by the defect pool model. This has important implications for the characterization, control, and improvement of thin $a$-Si:H-based solar cells as well as correlations of device properties with the corresponding intrinsic thin-film materials properties.

The authors acknowledge research support from the National Renewable Energy Laboratory under subcontract NDJ2-30630-01.

${ }^{1}$ M. Hack and M. Shur, J. Appl. Phys. 15, 997 (1985).

${ }^{2}$ J. Zimmer, H. Stiebig, J. Folsch, F. Finger, Th. Eickhoff, and H. Wagner, Mater. Res. Soc. Symp. Proc. 467, 735 (1997).

${ }^{3}$ M. J. Powell and S. C. Deane, Phys. Rev. B 53, 10121 (1996).

${ }^{4}$ R. S. Crandall and H. M. Branz, Conference Record of 21st IEEE PVSC (IEEE, New York, 1990), p. 1630.

${ }^{5}$ M. A. Kroon and R. A. C. M. M. van Swaaij, J. Appl. Phys. 90, 994 (2001).

${ }^{6}$ Y. Lee, A. S. Ferlauto, C. R. Wronski, Conference Record of 27th IEEE PVSC (IEEE, New York, 1997), p. 683.

${ }^{7}$ R. J. Koval, J. Koh, Z. Lu, L. Jiao, R. W. Collins, and C. R. Wronski, Appl. Phys. Lett. 75, 1553 (1999).

${ }^{8}$ K. Lips, Mater. Res. Soc. Symp. Proc. 377, 455 (1995).

${ }^{9}$ J. M. Pearce, R. J. Koval, A. S. Ferlauto, R. W. Collins, C. R. Wronski, J. Yang, and S. Guha, Appl. Phys. Lett. 77, 3093 (2000).

${ }^{10}$ W. Shockley and W. T. Read, Phys. Rev. 87, 835 (1952).

${ }^{11}$ L. Jiang, H. Lyou, S. Rane, E. Schiff, Q. Wang, and Q. Yuan, Mater. Res. Soc. Symp. Proc. 609, A18.3.1 (2000).

${ }^{12}$ C. van Berkel, M. J. Powell, A. R. Franklin, and I. D. French, J. Appl. Phys. 73, 5264 (1993).

${ }^{13}$ H. Matsuura, A. Matsuda, H. Okushi, and K. Tanaka, J. Appl. Phys. 58, 1578, (1985).

${ }^{14}$ K. W. Mitchell, D. Tanner, S. Vasquez, D. Willet, and S. Lewis, Conference Record of 18th IEEE PVSC (IEEE, New York, 1985), p. 914. 